\title{
Controlling the Uncontrolled Variation in the Diet Induced Obese Mouse by Microbiomic Characterization
}

\author{
Valeriia Bondarenko \\ University of Copenhagen \\ Cecillie Løkke \\ University of Copenhagen \\ Peter Dobrowolski \\ GVG Genetics \\ Caroline M. Junker Mentzel \\ University of Copenhagen \\ Josué L. Castro-Meija \\ University of Copenhagen \\ Camilla Hartmann Friis Hansen \\ University of Copenhagen \\ Dorte Bratbo Sørensen \\ University of Copenhagen \\ Dennis Sandris Nielsen \\ University of Copenhagen \\ Lukasz Krych \\ University of Copenhagen \\ Axel Kornerup Hansen ( $\square$ akh@sund.ku.dk) \\ University of Copenhagen
}

\section{Research Article}

Keywords: Variation, Diet, Microbiomic, B6NRj, ANOVA

Posted Date: November 30th, 2021

DOI: https://doi.org/10.21203/rs.3.rs-1061617/v1

License: (c) (7) This work is licensed under a Creative Commons Attribution 4.0 International License. Read Full License 


\section{Abstract}

C57BL/6NTac (B6NTac) and C57BL/6NRj (B6NRj) mice were fed a high calorie diet and treated with liraglutide. 42 mice would have been needed in an ordinary one-way ANOVA to show a reduction in glycosylated hemoglobin (HbA1c) in B6NTac mice, but incorporating the sequenced fecal microbiota in a twoway ANOVA reduced the group size needed to obtain a statistical significance to 12 mice. In B6NRj mice there was no impact of liraglutide on HbA1c neither with or without microbiota incorporation. In both sub-strains, the liraglutide effect on glucose tolerance and body weight was powered by incorporation of microbiota clusters. Although B6NTac mice were genetically far more conform than the B6NRj mice, incorporation of a genetic characterization by short tandem repeats had only little impact on the outcome of data evaluation. In conclusion, incorporation of microbiota characterisation powers data evaluation in diet induced obesity mouse strains, which are influenced by the microbiota.

\section{Introduction}

The diet-induced obese (DIO) mouse, i.e. C57BL/6 (B6) mice fed a high-calorie diet for up to four months is a commonly used animal model for diabetes and obesity ${ }^{1}$. It has an acceptable predictive validity, i.e. ability to predict an outcome in humans, compared many other animal models in biomedical research. For instance, the effect of glucagon-like peptide 1 receptor agonists (GLP-1RA), such as liraglutide, in DIO mice is highly comparable to humans ${ }^{2}$, i.e. it lowers body weight ${ }^{3}$, insulin resistance ${ }^{4}$ and long term blood glucose $(\mathrm{HbA1c})^{5}$. B6 sub-strains can be divided into a main cluster of sub-strains originating from either the Jackson Laboratories (C57BL/6J or B6J) or from the US National Institutes of Health (C57BL/6N or B6N). ${ }^{6}$ Even within these clusters sub-strains differ genetically ${ }^{6}$ and phenotypically ${ }^{7}$. For example, in some intervention studies in or lab we can get a significant difference in $\mathrm{HbA} 1 \mathrm{c}$, when using B6NTac from Taconic Biosciences (LI. Skensved, Denmark), while not when using B6NRj from Janvier Labs (Le Genest-Saint-Isle, France).

The high inter-individual variation of DIO mice ${ }^{8}$ reduces power and leads to the need for increased group sizes to show significant differences, as group sizes in animal studies are calculated from estimates on (a) standard deviation (s.d.) and (b) effect size combined with (c) the preferred power ( $\mu$ ) and (d) significance level $(p)^{9}$. In some studies the gut microbiota variation has been shown to account for $30-40 \%$ of variation in glucose related parameters, such as $\mathrm{HbA} 1 \mathrm{C}$ in the DIO model ${ }^{10}$, and the obese phenotype can be transferred between mice by fecal matter transplantation ${ }^{11}$. Therefore, microbiota impact may be a simple explanation for problems of obtaining enough power to show a specific difference. Hypothetically, some colonies of B6 mice may have a microbiota composition, which renders them less sensitive to eliciting certain glucose related responses Characterization by short tandem repeats (STRs), i.e. short runs of repetitive nucleotides in the non-coding DNA, reveals that even within a defined sub-strain mice are not genetically homogenic ${ }^{12}$.

Up till today variation in animal models has to a high extent been attempted to be controlled by standardization of factors such as diet and housing conditions ${ }^{13}$. It is, theoretically, possible to standardize an experiment by using the sub-strain most applicable for the purpose, as e.g. proposed within rheumatoid arthritis ${ }^{14}$. Recently it has been realized that much inter-individual variation is due to microbiota variation, ${ }^{15}$ and that microbiota composition differs substantially between colonies of the same strain ${ }^{7,16}$. Relatively little is still known to take robust decisions on what would be the most applicable and translational microbiota for diabetes and obesity research. Even mice of the same sub-strain may be delivered by the same vendor but from different breeding rooms with different microbiota ${ }^{17}$. In fact, the standardization approach has been questioned, as standardization in one environment may make experiments irreproducible in another environment ${ }^{18}$. As an alternative it has been proposed that the variation is systematically dispersed to each study group in a socalled multifactorial heterogenized design and accounted for in a multifactorial data evaluation, which can be shown to be more reproducible ${ }^{19,20}$.

Genomic and microbiomic characterizations have become cheaper and more available. Compared to single nucleotide polymorphisms (SNPs), STRs have a higher mutation rate which benefits the arising of new alleles and makes them highly polymorphic and make them an ideal tool for analysing genetic variability within the same colony of inbred mice ${ }^{12,21}$. If All mice of a study are microbiota characterized and clustered, as far as each cluster is represented in each group, it can be accounted for in multi-factorial data evaluation as for any other parameter. The STRs with the highest variability of alleles or a very even distribution of the different alleles may be identified, and be used as a factor in a multifactorial data evaluation. We, therefore, hypothesized that if all DIO mice in an intervention study were microbiota and genome characterized, this could be incorporated in data evaluation, and thereby lead to lower group sizes or increased power of a DIO mouse study. We test this we used HbA1c as primary read-out.

\section{Methods}

\section{Animals}

Experiments were in accordance with Danish Animal Experiments Act on protection of animals used for scientific purpose (Order 12 of 07/01/2016) and Directive 2010/63/EU of the European Parliament and the Council of 22/09/2010, and it was licensed accordingly by the Animal Experimentation Committee under the Danish Ministry of Food, Fisheries, and Agriculture (License No 2017-15-0201-01262. 32 C57BL/6NTac (B6NTac; Taconic Biosciences, Lille Skensved, Denmark) and 46 C57BL/6NRj (B6NRj; Janvier Labs, Le Genest-Saint-Isle, France) four week old male mice were feces sampled and ear-marked at the vendor three days before delivery (B6NTac) or at receipt (B6NRj) at our AAALAC-accredited barrier protected rodent facility, where there was $22^{\circ} \mathrm{C}+2^{\circ} \mathrm{C}, 55 \%$ $\pm 10 \%$ humidity, and light cycle 6 am to $6 \mathrm{pm}$. Mice were housed by four and changed bi-weekly in 1290D Eurostandard Type III cages (Scanbur A/S, Karlslunde, Denmark) with a wire lid and aspen bedding (Tapvei, Paekna, Estonia) with ad libitum access to bottled tap water, Enviro-Dri paper nesting material, aspen biting blocks $(\mathrm{L} \times \mathrm{W} \times \mathrm{H}: 50 \times 10 \times 10 \mathrm{~mm})$ in aspen wood (all Tapvei), a cardboard tube and a shelter (both from LBS serving Biotechnology, Horley, United Kingdom). Health monitoring according to FELASA guidelines ${ }^{22}$ revealed no pathogens. All mice were tunnel handled (from six weeks of age) or cupped without restraint (from 15 weeks of age) ${ }^{23}$.

\section{Experimental design}


Samples sizes were determined by power analysis ${ }^{9}$ on estimated intervention effect and variation in the primary read-out, i.e. $\mathrm{HbA} 1 \mathrm{c}$, based upon in-house experience primarily from B6NTac mice setting $p<0.05$ and power $=90 \%$. Group sizes for BL6NRj mice were increased with approximately $50 \%$. All mice were fed a synthetic high fat diet (HFD) (D12492 Research Diets, Brunswick, USA. Protein: 20\% kcal, Fat: 60\% kcal, Carbohydrate: $20 \%$ kcal) ad libitum from the age of four weeks to termination (Figure 1) monitoring food intake per cage and individual body weights Monday, Wednesday, and Friday. At 16 weeks of age mice were divided into liraglutide or vehicle treated groups (Taconic mice $n=16 /$ group; Janvier mice $n=23 /$ group) (Figure 1) and hereafter for four weeks treated subcutaneously with approximately $0.4 \mathrm{mg} / \mathrm{kg}$ liraglutide (as 1:49 dilution of Victoza $\rightarrow, 6 \mathrm{mg} / \mathrm{ml}$, Novo Nordisk, Denmark) once per day at $15-17$ p.m. in volumes of $0.1,0.125$ or $0.15 \mathrm{ml}$ depending on their body weight: $20-30 \mathrm{~g}, 31-40 \mathrm{~g}$ or $41-50 \mathrm{~g}$ respectively. Vehicle treated mice ( $\mathrm{n}=16)$ received the corresponding amount of sterile filtered dilution buffer $\left(50 \mathrm{mM} \mathrm{Na}_{2} \mathrm{HPO}_{4} \cdot 2 \mathrm{H}_{2} \mathrm{O}, 70 \mathrm{mM} \mathrm{NaCl}\right.$ and $0.05 \%$ polysorbate 80 , pH adjusted to 7.5$)$. For adaptation, the first two days of intervention experimental animals received a half dose of liraglutide (1:99 dilution) to avoid anorexia.

\section{Oral glucose tolerance test (OGTT), glycated hemoglobin (HbA1c), insulin and leptin measurements}

$\mathrm{HbA} 1 \mathrm{c}(\mathrm{mmol} / \mathrm{mol})$ was measured at 4 (baseline), 16 (pre-intervention) and 20 (post-intervention) weeks of age (DCA Vantage Analyzer, Siemens Healthcare Diagnostics, Ballerup, Denmark) on $1 \mu \mathrm{L}$ tail vein blood. To test oral glucose tolerance (OGTT) before and after liraglutide intervention fasting glucose ( $\mathrm{t}=0$ ) was measured (Freestyle Mini Glucometer, Hermedico, Copenhagen, Denmark) on mice fasted for six hours (from 7 a.m.) after tail vein puncture followed by gavage with $2 \mathrm{mg} / \mathrm{g}$ BW glucose ( $500 \mathrm{mg} / \mathrm{ml}$ glucose solution, Amgro l/S, Copenhagen, Denmark) and subsequent blood glucose monitoring at 15, $30,60,90$ and $120 \mathrm{~min}$. At termination, animals fasted for six hours were anesthetized with $0.1 \mathrm{ml} / 10 \mathrm{~g} \mathrm{BW}$ with 25\% Midazolam $\rightarrow(5 \mathrm{mg} / \mathrm{ml} \mathrm{midazolam}$, B.Braun, Melsungen, Germany) and $25 \%$ Hypnorm $\bigotimes(0.315 \mathrm{mg} / \mathrm{ml}$ of fentanyl citrate and $10 \mathrm{mg} / \mathrm{ml}$ of fluanisone, Skanderborg Pharmacy, Denmark) diluted in saline. Retro-orbital blood was collected into an autoclaved $1.5 \mathrm{ml}$ Safe-Lock Eppendorf ${ }^{\circledR}$ microcentrifuge tubes (Buch \& Holm A/S, Herlev, Denmark) and stored on ice for several hours, and later at $4^{\circ} \mathrm{C}$ for 1 day for blood coagulation. After centrifugation for 10 min at $10000 \mathrm{rpm}$ at $4^{\circ} \mathrm{C}$ supernatants were stored at $-80^{\circ} \mathrm{C}$. Animals were killed by cervical dislocation. Caecum contents were collected immediately after into sterile Eppendorf ${ }^{\circledR}$ tubes on dry ice during collection, with subsequent storage at $-80^{\circ} \mathrm{C}$. Before post-mortem sampling mice were blinded to the reader. Fasting serum insulin and leptin levels were measured (Mouse Metabolic Kit, Meso Scale Diagnostics, Rockville, United States) following the manufacturer's instructions. Samples from both strains were randomized and measured on one plate. Results were read using MESO QuickPlex SQ 120 (Mesoscale). Leptin measurements with values > $100000 \mathrm{pg} / \mathrm{ml}$ were reported as $100000 \mathrm{pg} / \mathrm{ml}$ due to limits in detection sensitivity of the test.

\section{Gut microbiota sequencing}

Faecal samples were stored at $-80^{\circ} \mathrm{C}$. DNA was purified using Bead-Beat Micro AX Gravity kit (A\&A Biotechnology, Gdynia, Poland, Cat\# 106-100) according to manufacturer's protocol. Purified DNA was stored at $-80^{\circ} \mathrm{C}$ until analysis. Concentration and purity were verified on Nano-Drop ND-1000 Spectrophotometer (Thermo Fisher Scientific). Based on Nano-Drop measurements the samples were normalised to $10 \mathrm{ng} / \mu \mathrm{L}$ with nuclease-free water using Biomek 4000 Workstation (Beckman Coulter Life Sciences, United States). The V3 variable region of the bacterial 16S rRNAgene was amplified using the primers NXt_388_F (5'-TCGTCGGCAG CGTCAGATGT GTATAAGAGA CAGACWCCTA CGGGWGGCAGCAG-3') and NXt_518_R (5'-GTCTCGTGGG CTCG-GAGATG TGTATAAGAG ACAGATTACC GCGGCTGCTGG-3') compatible with the Nextera Index Kit (Illumina, San Diego, United States). PCR was performed in a final reaction volume of $25 \mu \mathrm{L}$ composed of $5 \mu \mathrm{L}$ PCRBIO buffer, $0.5 \mu \mathrm{L}$ primer mix (10 uM), 0,25 $\mu \mathrm{L}$ PCRBIO HiFi polymerase (PCR Biosystems Ltd, London, UK), $5 \mu \mathrm{L}$ of genomic DNA, and nuclease-free water up to $25 \mu \mathrm{L}$. It was run on SureCycler 8800 (Agilent Technologies, Santa Clara, CA, USA), and the applied thermal cycling conditions were as follows: Enzyme activation for 2 min at $95^{\circ} \mathrm{C}$, 33 cycles of denaturation for $15 \mathrm{sec}$ at $95^{\circ} \mathrm{C}$, annealing for $15 \mathrm{sec}$ at $55^{\circ} \mathrm{C}$, and extension for 20 sec at $72{ }^{\circ} \mathrm{CC}$. Lastly, a final extension step for $20 \mathrm{sec}$ at $72{ }^{\circ} \mathrm{C}$. Quality of PCR amplicons was assessed by gel electrophoresis using $1.5 \%$ agarose gel and $0.5 \%$ TBE buffer at $120 \mathrm{~V}$ for $40 \mathrm{~min}$. A second PCR was run on SureCycler 8800 to label adapter-ligated DNA fragments with indices. PCR reactions contained $5 \mu \mathrm{L}$ PCRBIO buffer, $0.25 \mu \mathrm{L}$ PCRBIO HiFi polymerase, $2 \mu \mathrm{L}$ of each primer (P5 and P7), $2 \mu \mathrm{L}$ PCR product, and nuclease-free water to a total volume of $25 \mu \mathrm{L}$. Applied thermal cycling conditions were as follows: enzyme activation for 1 min at $95^{\circ} \mathrm{C}, 13$ cycles of denaturation for 15 sec at $95^{\circ} \mathrm{C}$, annealing for 15 sec and $55^{\circ} \mathrm{C}$, and extension for $15 \mathrm{sec}$ at $72{ }^{\circ} \mathrm{C}$. Lastly, a final extension step for 5 min at $72{ }^{\circ} \mathrm{C}$. Labelled adapter-ligated DNA fragments were purified by use of Biomek 4000 Workstation (Beckman Coulter Life Sciences, USA) using AMPure CP binding Beads pooled in equimolar concentrations and sequenced with the Illumina NextSeq550 platform. The raw dataset with pair-ended reads and corresponding quality scores was merged and trimmed using fastq_mergepairs and fastq_filter scripts implemented in the USEARCH pipeline as described previously ${ }^{24}$. Purging the dataset from chimeric reads and construction of zero radius Operational Taxonomic Units (zOTU) was conducted using the UNOISE. The Greengenes (13.8) 16S rRNA gene collection served as a reference database.

\section{Genetics}

The analysis of tail tips for genotyping was performed by GVG Genetic Monitoring GmbH as previously described ${ }^{12}$. A chromosomal panel of 244 highly polymorphic STR markers evenly distributed in the non-coding regions of the genome was used (Data S1). Snooplex FastPrep PCR reagents (GVG Genetic Monitoring, Leipzig, Germany) in combination with the GVG Genetic Monitoring standard marker panel (GVG Genetic Monitoring) were used for amplification of fluorescence-labelled PCR products (Bio-Rad C1000 Touch Thermal Cycler, Bio-Rad Laboratories, Hercules, USA). The standard cycling parameters were $94^{\circ} \mathrm{C}$ for $2 \mathrm{~min}$ followed by 38 cycles of $94^{\circ} \mathrm{C}$ for $30 \mathrm{~s}, 58^{\circ} \mathrm{C}$ for $1 \mathrm{~min}, 68^{\circ} \mathrm{C}$ for 2 min and a final elongation step of $68^{\circ} \mathrm{C}$ for $10 \mathrm{~min}$. Amplification products were electrophoresed on an ABI 3500 Genetic Analyzer (Applied Biosystems, Foster City, USA). Briefly, $1.8 \mu$ l of amplicons and $12 \mu$ of a $250: 1$ mixture of deionized formamide and internal lane size standard (MapMarker Custom, BioVentures Inc., Murfreesboro, USA; sizes: 60, 80, 90, 100, 120, 140, 160, 180, 200, $220,240,250,260,280,300,320,340,360,380,400,425,450,475,500,525$ and 550 bp labeled with Dy-632) were combined. PCR products were injected (15 s) and electrophoresed at $15 \mathrm{kV}$ in Performance Optimized Polymer 4 (POP4, Applied Biosystems). Data analysis was performed with GeneMapper v5 (Applied Biosystems).

\section{Statistics}


OGTT was calculated as area under the curve (AUC). For OGTT, body weight and HbA1c the the effectss were expressed as $\triangle$-values, i.e. the percentage difference between pre- and post-intervention values out of the pre-intervention value. Data were tested for Gaussian distribution by Anderson-Darling test and equal variances by Levene's test (Minitab 19.0, Minitab Inc., Coventry, UK). For further analysis as factors in two-way ANOVAs all mice were clustered after their microbiome at time 1 and 2 in a group-independent cluster analysis using Bray-Curtis dissimilarities on zOTU tables rarefied to 10,000 reads. Hierarchical clustering was based on the Ward's method and the optimal number of clusters were chosen based on ensuring the maximum possible number of clusters, when each cluster was represented in both treatment and control groups. One-hundred permutations on a generalized-linear model (GML - "Imer4" package R, R Statistics, New York, USA) were performed and final cluster denotation was as random effect for each permutation. For further analysis as factors in twoway ANOVAs from each we selected for each sub-strain the STRs with the most even distribution of alleles within the locus, and those which had the highest number of different alleles within the locus. The degree of conformity of the genotype of an individual with the consensus STR-genotype of its strain was calculated by comparing STR alleles for all STR markers. The value of 1 was allocated if both alleles were identical with the consensus allele, a value of 0 if both alleles differed and a value of 0.75 if there is a heterozygous matched. The resulting sum of all values was then divided by the number of markers and a percentage figure describing the match between the individual and the consensus STR-genotype was obtained.

All data were compared by both a one-tailed, one-way ANOVA (Minitab: ANOVA/One-Way) as well as two-way ANOVAs with the factors treatment and either cluster or allele (Minitab, ANOVA/General Linear Model/Fit general linear model). For one-way ANOVA the observed differences and standard deviations (s.d.) were used in a power analysis for minimum sample size and power estimation (Minitab, Power and sample size/One-Way ANOVA), while for the two-way ANOVAs the mean weighted differences and s.d. based upon the differences between treatments and s.d. within each cluster (Table S2) were used for estimation of the minimum sample size and power estimation (Minitab, Power and sample size/General full factorial design) (Figure 1). Data not following a Gaussian distribution and/or having equal variances were ranked before test.

Bacterial abundances from feces sampled at time 1 and 2 and genetic conformities were compared between sub-strains by a t-test with Welsch's correction (GraphPad Prism, San Diego, USA). Bacterial abundances from both feces and cecum after liraglutide treatment (time 2) were checked for normality (Prism) and equal variances (Minitab) and ranked in case of failing the assumptions before comparing by a two-way ANOVA (Minitab, ANOVA/General Linear Model/Fit general linear model) with the factors strain and treatment. Multiple comparison p-values were corrected by the Holm-Sidak correction (Prism).

\section{Results}

\section{The two sub-strains differed essentially in microbiota composition.}

B6NTac mice harboured Bifidobacterium spp at time 1, while these were absent in B6NRj mice at time 1 and in both substrains on time 2 (Table S1). B6NTac mice had more Bacteroides spp., while the B6NRj mice had more Prevotella spp. (Table S1), and at time 2 Prevotella spp. were absent in B6NTac mice (Table S2 and S3). B6NTac mice had more Lactobacillus spp. at time 1, while B6NRj had more Lactococcus spp. at time 2 (Table S1). At both times and both in feces and cecum the relative abundances of Akkermansia muciniphila was highest in the B6NRj mice (Table S1-3). Liraglutide increased the relative abundances of Lactobacillus spp, and Clostridiaceae in feces and cecum and Enterococcaceae in feces (Table S2), while it decreased the relative abundances to below detection of segmented filamentous bacteria (Candidatus arthromitus) in feces of both sub-strains (Table S2). B6NTac could be separated into three microbiomic clusters at time 1 and 2, while B6NRj could be separated into four clusters at time 1 and 2. One B6NTac mouse at time 2, 8 B6NRj mice at time 1 and 11 B6NRj mice at time 2 did not yield enough reads to be clustered (Data S2).

\section{Some STRs of B6NRj mice were highly polymorphic}

The genetic conformity of the B6NTac mice was significantly higher than the B6NRj mice ( $p<0.0001$, Figure 2). STRs of B6NTac mice were not polymorphic, as none of them expressed more than three different alleles, while in the B6NRj mice three STRs expressed five-six different alleles (Table 2). The STRs D1S113, D9S218 and D5S519 in the B6NTac mice and the STRs D11S112 and D15S215 in B6NRj mice showed the most even distribution of the alleles, while (Table 2).

Table 1. 


\begin{tabular}{|c|c|c|c|c|c|c|c|c|c|}
\hline & $\begin{array}{l}\triangle O G T T \\
\text { AUC\% }\end{array}$ & $\begin{array}{l}\Delta \text { Body } \\
\text { weight } \%\end{array}$ & $\begin{array}{l}\text { Primary } \\
\text { readout }\end{array}$ & $\begin{array}{l}\text { Insulin } \\
\mathrm{pg} / \mathrm{ml}\end{array}$ & Leptin pg/m* & $\begin{array}{l}\text { Fasting } \\
\text { glucose } \\
\text { mmol/l }\end{array}$ & $\triangle \mathrm{OGTT}$ AUC\% & $\begin{array}{l}\Delta \text { Body } \\
\text { weight \% }\end{array}$ & $\begin{array}{l}\text { Primar } \\
\text { readou }\end{array}$ \\
\hline $\begin{array}{l}\text { Group size } \\
\text { in study } \mathrm{N}\end{array}$ & 16 & 16 & 16 & 16 & 16 & 16 & 23 & 23 & 23 \\
\hline $\begin{array}{l}\text { Liraglutide } \\
\text { (Mean } \pm \text { s.d.) }\end{array}$ & $-40.32 \pm 13.71$ & $-11.94 \pm 4.12$ & $-11.60 \pm 16.29$ & $1235 \pm 780$ & $7490 \pm 5304$ & $5.81 \pm 0.93$ & $-1.47 \pm 22.25$ & $-10.52 \pm 4.05$ & $-4.27 \pm^{-}$ \\
\hline $\begin{array}{l}\text { Control } \\
\text { ((Mean } \pm \text { s.d.) }\end{array}$ & $-14.41 \pm 18.77$ & $0.09 \pm 3.55$ & $0.09 \pm 16.27$ & $1568 \pm 967$ & $23688 \pm 12103$ & $7.09 \pm 1.25$ & $-16.51 \pm 19.90$ & $3.48 \pm 5.21$ & $-2.93 \pm$ \\
\hline \multicolumn{10}{|l|}{$\begin{array}{l}\text { One-way } \\
\text { ANOVA }\end{array}$} \\
\hline Effect & -25.91 & -12.03 & -11.69 & -335 & -16198 & -1.28 & -15.05 & -14.00 & -1.34 \\
\hline Pooled s.d. & 16.44 & 3.84 & 16.28 & 878 & 9344 & 1.1 & 21.11 & 4.67 & 15.64 \\
\hline $\begin{array}{l}\text { Significance, } \\
\text { difference } \\
\text { between } \\
\text { treatments, } \\
\text { p }\end{array}$ & 0.000 & 0.000 & 0.051 & 0.292 & $0.000 \#$ & 0.003 & 0.020 & 0.000 & 0.772 \\
\hline Power & 0.99 & 1.00 & 0.50 & 0.18 & $1.00 \#$ & 0.89 & 0.66 & 1.00 & 0.06 \\
\hline $\begin{array}{l}\text { Group size } \\
\text { for } p<0.05 \\
\text { and } \\
\text { power }>0.9\end{array}$ & 10 & 4 & 42 & 146 & $8 \#$ & 17 & 43 & 4 & 2864 \\
\hline \multicolumn{10}{|l|}{$\begin{array}{l}\text { Two-way } \\
\text { ANOVA }\end{array}$} \\
\hline \multicolumn{10}{|l|}{$\begin{array}{l}\text { Microbiome } \\
\text { time } 1\end{array}$} \\
\hline $\begin{array}{l}\text { Efficient } \\
\text { group size }\end{array}$ & 16 & 16 & 16 & 16 & 16 & 16 & 15 & 15 & 15 \\
\hline $\begin{array}{l}\text { Weighted } \\
\text { effect }\end{array}$ & -26.66 & -12.28 & -13.00 & -457 & -16472 & -1.23 & -17.85 & -13.38 & -1.99 \\
\hline Pooled s.d. & 16.69 & 3.92 & 16.49 & 803 & 9422 & 1.10 & 20.11 & 4.80 & 16.11 \\
\hline $\begin{array}{l}\text { Significance, } \\
\text { difference } \\
\text { between } \\
\text { treatments, } \\
\text { p }\end{array}$ & 0.000 & 0.000 & 0.033 & 0.133 & $0.000 \#$ & 0.001 & 0.034 & 0.000 & 0.681 \\
\hline $\begin{array}{l}\text { Significance, } \\
\text { difference } \\
\text { between } \\
\text { clusters, p }\end{array}$ & 0.747 & 0.307 & 0.164 & 0.040 & $0.230 \#$ & 0.270 & 0.968 & 0.415 & 0.435 \\
\hline $\begin{array}{l}\text { Power at } \\
\mathrm{N}_{\text {one-way }} \\
\text { animals }\end{array}$ & 1.00 & 1.00 & 0.80 & 0.50 & $1.00 \#$ & 0.98 & 0.87 & 1.00 & 0.07 \\
\hline $\begin{array}{l}\text { Group size } \\
\text { for } p<0.05 \\
\text { and } \\
\text { power }>0.9\end{array}$ & 6 & 3 & 21 & 40 & $5 \#$ & 11 & 17 & 3 & 830 \\
\hline \multicolumn{10}{|l|}{$\begin{array}{l}\text { Microbiome } \\
\text { time } 2\end{array}$} \\
\hline $\begin{array}{l}\text { Efficient } \\
\text { group size }\end{array}$ & 15 & 15 & 15 & 15 & 15 & 15 & 12 & 12 & 12 \\
\hline $\begin{array}{l}\text { Weighted } \\
\text { effect }\end{array}$ & -28.54 & -12.48 & -17.20 & -407 & -16610 & -1.35 & -27.30 & -14.67 & -0.97 \\
\hline Pooled s.d. & 17.23 & 3.71 & 15.95 & 863 & 10038 & 1.12 & 17.46 & 4.84 & 13.68 \\
\hline $\begin{array}{l}\text { Significance, } \\
\text { difference } \\
\text { between } \\
\text { treatments, } \\
p\end{array}$ & 0.000 & 0.000 & 0.038 & 0.154 & $0.000 \#$ & 0.013 & 0.004 & 0.000 & $0.805 \#$ \\
\hline
\end{tabular}




\begin{tabular}{|c|c|c|c|c|c|c|c|c|c|}
\hline $\begin{array}{l}\text { Significance, } \\
\text { difference } \\
\text { between } \\
\text { clusters, p }\end{array}$ & 0.361 & 0.905 & 0.376 & 0.217 & $0.926 \#$ & 0.614 & 0.970 & 0.337 & $0.155 \#$ \\
\hline Power & 0.99 & 1.00 & 0.96 & 0.34 & $1.00 \#$ & 0.98 & 0.99 & 1.00 & $0.06 \#$ \\
\hline $\begin{array}{l}\text { Group size } \\
p<0.05 \text { and } \\
\text { power }>0.9\end{array}$ & 6 & 2 & 12 & 58 & 4\# & 10 & 7 & 3 & 1482\# \\
\hline \multicolumn{10}{|c|}{ \# Tested on ranked data due failure in unequal variances } \\
\hline Group size & $31-40$ & \multicolumn{2}{|c|}{$21-30$} & \multicolumn{2}{|c|}{$10-20$} & $<10$ & & & \\
\hline
\end{tabular}

Table 2

\begin{tabular}{|c|c|c|}
\hline & B6NRj & B6NTac \\
\hline & STRs & STRs \\
\hline & $N(S T R)=243$ & $N(S T R)=243$ \\
\hline \multicolumn{3}{|c|}{ Expression of the most prevalent allele in the STRs } \\
\hline $100 \%$ & $72(29.6 \%)$ & $138(56.8 \%)$ \\
\hline$\geq 90 \%<100 \%$ & $101(41.6 \%)$ & $89(36.6 \%)$ \\
\hline$\geq 80 \%<90 \%$ & $36(14.8 \%)$ & $10(4.1 \%)$ \\
\hline$\geq 70 \%<80 \%$ & $14(5.8 \%)$ & $3(1.2 \%)$ \\
\hline$\geq 60 \%<70 \%$ & $8(3.29 \%)$ & $2(0.8 \%)^{d}$ \\
\hline$\geq 50 \%<60 \%$ & $10(4.1 \%)$ & $1(0.4 \%)^{e}$ \\
\hline$\geq 40 \%<50 \%$ & $2(0.8 \%)^{a}$ & $0(0.0 \%)$ \\
\hline \multicolumn{3}{|c|}{ No of alleles expressed in the STRs } \\
\hline 6 & $2(0.8 \%)^{b}$ & $0(0.0 \%)$ \\
\hline 5 & $1(0.4 \%)^{c}$ & $0(0.0 \%)$ \\
\hline 4 & $7(2.9 \%)$ & $0(0.0 \%)$ \\
\hline 3 & $48(19.8 \%)$ & $31(12.8 \%)$ \\
\hline 2 & $113(46.5 \%)$ & $74(30.5 \%)$ \\
\hline 1 & $72(29.6 \%)$ & $138(56.8 \%)$ \\
\hline \multicolumn{3}{|c|}{ a D11S112, D15S215; b D12S206, D9S312; c D16S147; d D1S113, D9S218; e DXS312 } \\
\hline
\end{tabular}

HbA1c only had a significant effect, if microbiomic clusters were incorporated in data evaluation, and only in B6NTac.

HbA1c was only borderline significantly lowered by the Liraglutide treatment in B6NTac mice $(p=0.051$, Table 1$)$, while the effect was minimal in B6NRj mice $(p=0.190$, Table 1). A two-way ANOVA including the microbiomic clusters revealed a significant effect of liraglutide at both time $1(p=0.033)$ and $2(p=$ 0.038) (Table 1). The group size estimated for obtaining significance on the HbA1c effect in B6NTac mice was estimated to be 42 in a one-way ANOVA, while in a two-way ANOVA it was 21 at time 1 and 12 at time 2 (Table 1). Inclusion of the microbiomic clusters in two-way ANOVAs did not change anything in the B6NRj mice (Table 1).

\section{Liraglutide had the expected effect and by including the microbiomic clusters in a two-way ANOVA power was increased}

Liraglutide had the expected effect on glucose intolerance (OGTT), body weight, leptin and blood glucose (Data S3). Liraglutide lowered glucose intolerance (OGTT) in both B6NTac ( $p=0.000$, Table 1$)$ and B6NRj $(p=0.020$, Table 1) mice. However, 43 B6NRj mice would be needed in each group to obtain a power of 0.90 (Table 1) and the actual power with 23 mice was only 0.66 , while only 10 B6NTac mice would be needed and the actual power with the 16 mice was 0.99 (Table 1). In the B6NRj mice microbiomic cluster inclusion in a two-way ANOVA decreased the estimated group size needed to show an OGTT effect to 7 at time 2 and increased the actual power to 0.99 in spite of the fact that the lack of reads at time 2 reduced the efficient group size from 23 to 12 (Table 1 ). Fasting blood glucose was significantly lowered by liraglutide in both strains $(p(B 6 N R j)=0.001, p(B 6 N T a c)=0.003)$, and there was some increase in power and decrease in group sizes by a microbiomic cluster including two-way ANOVA. This was particularly evident in the B6NTac mice, in which it reduced group sizes and increased power from 17 and 0.89 to 10-11 and 0.98, while in B6NRj mice at time 2 the reduction in efficient group size from 23 to 12 due to the lack of reads seemed to be counterproductive (Table 1). One-way ANOVA for the effect on body weight and leptin was powerful ( $p=0.000-0.001)$ making it 
difficult to assess whether a microbiomic cluster two-way ANOVA had any powering effect on any of the strains (Table 1). B6NRj mice showed a significantly insulin lowering effect of liraglutide in a microbiomic cluster two-way ANOVA at time 1 but not in a one-way ANOVA $(p=0.022$, Table 1$)$.

Including the STRs in a two-way ANOVA had little impact on power and group sizes.

In neither of the sub-strains the inclusion of the selected STRs as factors in a two-way ANOVA had a major impact on the power and the estimated group sizes (Table 3 and 4). Most remarkably inclusion of D12S206 resulted in a p $=0.006$, a power of 0.93 and an estimated group size of 21 needed for evaluation of insulin compared to $p=0.022$, power $=0.64$ and an estimated group size of 44 if based upon a one-way ANOVA (Table 4). 
Table 3

\begin{tabular}{|c|c|c|c|c|c|c|}
\hline & $\begin{array}{l}\triangle O G T T \\
\text { AUC\% }\end{array}$ & $\underset{\%}{\Delta}$ Body weight & $\begin{array}{l}\text { Primary readout } \\
\Delta \mathrm{HbA} 1 \mathrm{c}^{*}\end{array}$ & $\begin{array}{l}\text { Insulin } \\
\mathrm{pg} / \mathrm{ml}\end{array}$ & Leptin pg/ml* & $\begin{array}{l}\text { Fasting glucose } \\
\mathrm{mmol} / \mathrm{l}\end{array}$ \\
\hline Group size $_{y}$ & 16 & 16 & 16 & 16 & 16 & 16 \\
\hline Liraglutide (Mean \pm s.d.) & $-40.32 \pm 13.71$ & $-11.94 \pm 4.12$ & $-11.60 \pm 16.29$ & $1235 \pm 780$ & $7490 \pm 5304$ & $5.81 \pm 0.93$ \\
\hline Control (Mean \pm s.d.) & $-14.41 \pm 18.77$ & $0.09 \pm 3.55$ & $0.09 \pm 16.27$ & $1568 \pm 967$ & $23688 \pm 12103$ & $7.09 \pm 1.25$ \\
\hline \multicolumn{7}{|l|}{ One-way ANOVA } \\
\hline Effect & -25.91 & -12.03 & -11.69 & -335 & -16198 & -1.28 \\
\hline Pooled s.d. & 16.44 & 3.84 & 16.28 & 878.44 & 6.84 & 1.1 \\
\hline $\begin{array}{l}\text { Significance, difference } \\
\text { treatments, } \mathrm{p}\end{array}$ & 0.000 & 0.000 & 0.051 & 0.292 & 0.000 & 0.003 \\
\hline Power $\mu$ & 0.99 & 1.00 & 0.50 & 0.18 & 1.00 & 0.89 \\
\hline $\begin{array}{l}\text { Group size for } p<0.05 \text { and } \\
\text { power }>0.9\end{array}$ & 10 & 4 & 42 & 146 & 8 & 17 \\
\hline \multirow[t]{2}{*}{ Two-way ANOVA } & \multicolumn{6}{|c|}{ Genome (STRs with most even gene frequencies) } \\
\hline & \multicolumn{6}{|l|}{ D1S113 } \\
\hline Weighted effect & 22.86 & 12.40 & 12.39 & 167 & -16401 & 1.18 \\
\hline Pooled s.d. & 15.23 & 3.25 & 17.22 & 870.43 & 9695.3 & 1.03 \\
\hline $\begin{array}{l}\text { Significance, difference } \\
\text { treatments, } p\end{array}$ & 0.000 & 0.000 & 0.054 & 0.555 & $0.000 \#$ & 0.002 \\
\hline Significance, difference alleles, $\mathrm{p}$ & 0.099 & 0.016 & 0.865 & 0.301 & $0.323 \#$ & 0.113 \\
\hline Power & 0.99 & 1.00 & 0.65 & 0.09 & $1.00 \#$ & 0.98 \\
\hline \multirow{2}{*}{$\begin{array}{l}\text { Group size for } p<0.05 \text { and } \\
\text { power }>0.9\end{array}$} & 7 & 2 & 28 & 386 & $5 \#$ & 12 \\
\hline & \multicolumn{6}{|l|}{ D9S218 } \\
\hline Weighted effect & -22.78 & -11.72 & -5.83 & -433 & -14507 & -1.27 \\
\hline Pooled s.d. & 17.24 & 3.68 & 14.58 & 823.69 & 9599.22 & 1.08 \\
\hline $\begin{array}{l}\text { Significance, difference } \\
\text { treatments, } \mathrm{p}\end{array}$ & 0.001 & 0.000 & 0.254 & 0.129 & $0.000 \#$ & 0.002 \\
\hline Significance, difference alleles, $p$ & 0.877 & 0.232 & 0.013 & 0.044 & $0.482 \#$ & 0.267 \\
\hline Power & 0.99 & 1.00 & 0.27 & 0.44 & 0.99\# & 0.99 \\
\hline \multirow{2}{*}{$\begin{array}{l}\text { Group size for } p<0.05 \text { and } \\
\text { power }>0.9\end{array}$} & 8 & 2 & 80 & 47 & $6 \#$ & 10 \\
\hline & \multicolumn{6}{|l|}{ DXS312 } \\
\hline Weighted effect & $-26,34$ & $-11,98$ & -11.38 & -342 & -15757 & -1.28 \\
\hline Pooled s.d. & 17.85 & 4,20 & 17.55 & 948,53 & 9897.92 & 1.19 \\
\hline $\begin{array}{l}\text { Significance, difference } \\
\text { treatments, } p\end{array}$ & 0.000 & 0.000 & 0.062 & 0.294 & $0.533 \#$ & 0.003 \\
\hline Significance, difference alleles, $p$ & 0.569 & 0.787 & 0.699 & 0.861 & $0.000 \#$ & 0.981 \\
\hline Power $\mu$ & 1.00 & 1.00 & 0.72 & 0.29 & 1.00\# & 0.99 \\
\hline $\begin{array}{l}\text { Group size for } p<0.05 \text { and } \\
\text { power }>0.9\end{array}$ & 6 & 3 & 26 & 82 & $5 \#$ & 10 \\
\hline \multicolumn{7}{|c|}{ \# Tested on ranked data due failure in equal variances } \\
\hline Group size & $31-40$ & $21-30$ & $10-20$ & $<10$ & & \\
\hline
\end{tabular}




\begin{tabular}{|c|c|c|c|c|c|c|}
\hline & $\begin{array}{l}\triangle O G T T \\
\text { AUC\% }\end{array}$ & $\underset{\%}{\Delta \text { Body weight }}$ & $\begin{array}{l}\text { Primary readout } \\
\Delta \mathrm{HbA} 1 \mathrm{c} \%^{*}\end{array}$ & $\begin{array}{l}\text { Insulin } \\
\mathrm{pg} / \mathrm{ml}\end{array}$ & Leptin pg/ml* & $\begin{array}{l}\text { Fasting glucose } \\
\mathrm{mmol} / \mathrm{h}\end{array}$ \\
\hline Group size $_{y}$ & 23 & 23 & 23 & 23 & 23 & 23 \\
\hline Liraglutide (Mean \pm s.d.) & $-1.47 \pm 22.25$ & $-10.52 \pm 4.05$ & $-4.27 \pm 18.56$ & $1769 \pm 2247$ & $12865 \pm 11078$ & $4.82 \pm 0.70$ \\
\hline Control (Mean \pm s.d.) & $-16.51 \pm 19.90$ & $3.48 \pm 5.21$ & $-2.93 \pm 12.02$ & $3731 \pm 3265$ & $43131 \pm 24610$ & $6.00 \pm 1.35$ \\
\hline \multicolumn{7}{|l|}{ One-way ANOVA } \\
\hline Effect & -15.05 & -14.00 & -1.34 & -1962 & -30266 & -1.18 \\
\hline Pooled s.d. & 21.11 & 4.67 & 15.64 & 2803 & 19083 & 1.08 \\
\hline $\begin{array}{l}\text { Significance, difference } \\
\text { treatments, } p\end{array}$ & 0.020 & 0.000 & 0.772 & 0.022 & $0.000 \#$ & 0.001 \\
\hline Power $\mu$ & 0.66 & 1.00 & 0.06 & 0.64 & $1.00 \#$ & 0.95 \\
\hline $\begin{array}{l}\text { Group size for } \mathrm{p}<0.05 \text { and } \\
\text { power }>0.9\end{array}$ & 43 & 4 & 2864 & 44 & $7 *$ & 19 \\
\hline \multirow[t]{2}{*}{ Two-way ANOVA } & \multicolumn{6}{|c|}{ Genome (STRs with most even gene frequencies) } \\
\hline & \multicolumn{6}{|l|}{ D11S112 } \\
\hline Weighted effect & -15.71 & -13.76 & -1.21 & -1940 & -27115 & -1.26 \\
\hline Pooled s.d. & 22.25 & 4.85 & 14.71 & 2871 & 16936 & 1.18 \\
\hline $\begin{array}{l}\text { Significance, difference } \\
\text { treatments, } p\end{array}$ & 0.000 & 0.018 & 0.742 & 0.027 & $0.001 \#$ & 0.000 \\
\hline Significance, difference alleles, $p$ & 0.969 & 0.492 & 0.065 & 0.741 & $0.920 \#$ & 0.768 \\
\hline Power $\mu$ & 0.7 & 1.00 & 0.06 & 0.66 & $1.00 \#$ & 0.98 \\
\hline \multirow{2}{*}{$\begin{array}{l}\text { Group size for } p<0.05 \text { and } \\
\text { power }>0.9\end{array}$} & 36 & 3 & 2575 & 39 & $6 \#$ & 16 \\
\hline & \multicolumn{6}{|l|}{ D15S215 } \\
\hline Weighted effect & -14.72 & -13.98 & -3.46 & -2119 & -34290 & -1.45 \\
\hline Pooled s.d. & 20.62 & 4.54 & 16.50 & 2734 & 15209 & 0.80 \\
\hline $\begin{array}{l}\text { Significance, difference } \\
\text { treatments, } p\end{array}$ & 0.027 & 0.000 & 0.506 & 0.024 & $0.000 \#$ & 0.000 \\
\hline Significance, difference alleles, $p$ & 0.717 & 0.250 & 0.612 & 0.698 & $0.158 \#$ & 0.104 \\
\hline Power $\mu$ & 0.78 & 1.00 & 0.1 & 0.85 & $1.00 \#$ & 1.00 \\
\hline \multirow{3}{*}{$\begin{array}{l}\text { Group size for } p<0.05 \text { and } \\
\text { power }>0.9\end{array}$} & 31 & 3 & 351 & 27 & 4\# & 6 \\
\hline & \multicolumn{6}{|c|}{ Genome (STRs with highest polymorphism) } \\
\hline & \multicolumn{6}{|l|}{ D9S312 } \\
\hline Weighted effect & -13.26 & -12.60 & -0.14 & -1453 & -26332.41 & -0.95 \\
\hline Pooled s.d. & 20.36 & 4.95 & 16.44 & 2377 & 19204 & 1.12 \\
\hline $\begin{array}{l}\text { Significance, difference } \\
\text { treatments, } p\end{array}$ & 0.153 & 0.758 & 0.605 & 0.089 & $0.708 \#$ & 0.721 \\
\hline Significance, difference alleles, $p$ & 0.025 & 0.000 & 0.990 & 0.058 & $0.000 \#$ & 0.004 \\
\hline Power $\mu$ & 0.62 & 1.00 & 0.05 & 0.55 & $1.00 \#$ & 0.87 \\
\hline \multirow{2}{*}{$\begin{array}{l}\text { Group size for } \mathrm{p}<0.05 \text { and } \\
\text { power }>0.9\end{array}$} & 42 & 4 & 240197 & 48 & 8\# & 25 \\
\hline & \multicolumn{6}{|l|}{ D12S206 } \\
\hline Weighted effect & -13.05 & -14.07 & -1.87 & -2635 & -33355.89 & -1.15 \\
\hline pooled SD & 21.92 & 4.72 & 16.16 & 2768 & 17969.84 & 1.15 \\
\hline $\begin{array}{l}\text { Significance, difference } \\
\text { treatments, } p\end{array}$ & 0.040 & 0.000 & 0.959\# & 0.006 & 0.000 & 0.002 \\
\hline
\end{tabular}




\begin{tabular}{|c|c|c|c|c|c|c|}
\hline & $\begin{array}{l}\triangle O G T T \\
\text { AUC\% }\end{array}$ & $\underset{\%}{\Delta}$ Body weight & $\begin{array}{l}\text { Primary readout } \\
\Delta \mathrm{HbA1c \% *}\end{array}$ & $\begin{array}{l}\text { Insulin } \\
\mathrm{pg} / \mathrm{ml}\end{array}$ & Leptin pg/ml* & $\begin{array}{l}\text { Fasting glucose } \\
\mathrm{mmol} / \mathrm{l}\end{array}$ \\
\hline Significance, difference alleles, $p$ & 0.379 & 0.314 & $0.504 \#$ & 0.490 & 0.211 & 0.950 \\
\hline Power $\mu$ & 0.5 & 1.00 & $0.09 \#$ & 0.93 & 1.00 & 0.96 \\
\hline \multirow{2}{*}{$\begin{array}{l}\text { Group size for } p<0.05 \text { and } \\
\text { power>0.9 }\end{array}$} & 53 & 3 & $476 \#$ & 21 & 5 & 19 \\
\hline & \multicolumn{6}{|c|}{ D16S147 } \\
\hline Weighted effect & -14.07 & -12.98 & -1.58 & -1932.67 & -30082 & -1.18 \\
\hline pooled SD & 20.35 & 4.41 & 16.26 & 2676.17 & 20096 & 1.12 \\
\hline $\begin{array}{l}\text { Significance, difference } \\
\text { treatments, } \mathrm{p}\end{array}$ & 0.025 & 0.000 & 0.803 & 0.028 & 0.000 & 0.001 \\
\hline Significance, difference alleles, $p$ & 0.299 & 0.105 & 0.829 & 0.439 & 0.833 & 0.573 \\
\hline Power $\mu$ & 0.75 & 1.00 & 0.06 & 0.79 & 0.99 & 0.99 \\
\hline $\begin{array}{l}\text { Group size for } p<0.05 \text { and } \\
\text { power }>0.9\end{array}$ & 33 & 3 & 1632 & 31 & 8 & 15 \\
\hline \multicolumn{7}{|c|}{ \# Tested on ranked data due failure in equal variances } \\
\hline Group size & $31-40$ & $21-30$ & $10-20$ & $<10$ & & \\
\hline
\end{tabular}

\section{Discussion}

This study shows that inclusion of the microbiota clusters from a sequencing based characterisation as a factor in a two-way ANOVA increases power in some key parameters of the DIO model. This increased the chances of showing a liraglutide lowering impact on HbA1c in the B6NTac mice. In contrast, the effect in B6NRj mice was either absent or minimal, and considering the microbiota characterisation in a two-way ANOVA did not influence this, which strengthens the conclusion that there probably is no effect of liraglutide on HbA1c in B6NRj mice. As HbA1c in some mice seems strongly correlated to gut microbiota composition ${ }^{25}$, and the effect of liraglutide is partly mediated by induced changes in the gut microbiota ${ }^{26}$, a reasonable explanation could be that a deviating microbiota in the B6NRj makes them rather resistant to HbA1c changes. B6NTac were in contrast to B6NRj mice colonized with Bifidobacterium spp., while B6NRj harboured higher relative abundances of $A$. muciniphila both of which are known to control and alleviate the development of diet-induced obesity in both mice ${ }^{27,28}$ and humans ${ }^{29,30}$. In B6NTac mice the family Lactobacillaceae was dominated by Lactobacillus spp., which were increased in abundance by the liraglutide treatment, while it was dominated by Lactococcus spp. in B6NRj mice. B6NTac mice had more Bacteroides spp., while the B6NRj mice had more Prevotella spp. This is equivalent to humans in which patients with a microbiota dominated by Bacteroides spp. have a higher risk of developing type 2 diabetes ${ }^{31}$, but they are also more responsive to certain interventions compared to patients with a microbiota dominated by Prevotella spp. 32 .

As liraglutide lowers HbA1c in humans ${ }^{5}$, B6NTac compared to B6NRj seems to have a higher predictive validity. Still, the liraglutide induced lower body weight and increased glucose intolerance, known from humans ${ }^{3,4}$, could be shown in both B6NTac and B6NRj mice even in a one-way ANOVA. Inclusion of the microbiota clusters in a two-way ANOVA also increased the power of showing an impact on OGTT in the B6NTac mice.

It is critical for the organization of the mice into clusters that there is a sufficient number of reads in the sequencing for each mouse. In the calculation of group sizes and power for the multifactorial evaluation, we used the weighted average effect in the equation. Normally, group sizes and power are determined by the maximum effect, and this more conservative estimate may lead to a less optimistic but eventually more reachable estimate of group sizes.

With only $29.6 \%$ of the B6NRj STRs being $100 \%$ homozygous and a STR conformity between 91 and $97 \%$ this sub-strain may not be in full accordance with expectations to an inbred mouse. However, in $86 \%$ of the B6NRj STRs the most prevalent allele had a frequency of more than $80 \%$. Therefore, most likely this genetic heterogeneity is more to be regarded as a trace contamination without the same impact on the parameter responses as the microbiota fluctuations. Our two-way ANOVAs did not indicate that this heterogeneity could explain the lowered or lacking effect of liraglutide on OGTT and HbA1c in the B6NRj mice.

It is an obligation whenever using animals for research to reduce the number of animals used in individual studies as one of the three 3 R's, i.e. replacement, reduction and refinement ${ }^{33}$. Strong microbiota impact has also been described for a number of animal models within a broad spectrum of other biomedical disciplines ${ }^{34}$, such as brain-related ${ }^{35}$, autoimmune ${ }^{36}$, allergic ${ }^{37}$ diseases, and cancer ${ }^{38}$ diseases Therefore, our method would likely also be applicable for other models, as well.

In conclusion, the inclusion of microbiota clusters in a two-way ANOVA in the evaluation of the glucose related effects of an anti-diabetic and anti-obesity intervention in the DIO mouse model is an efficient tool for increasing power and reducing group sizes in those B6 mouse sub-strains, which have a parameter influencing microbiota.

\section{Declarations}

\section{Acknowledgements}


Helene Farlov and Mette Nelander are kindly acknowledged for taking care of the animals. Sofie Kromann, Maria Bernadette Bergh Ebert and Amalie Winter Arildsen are kindly acknowledged for help in conduction of experimental procedures and post-mortem sample collection.

\section{Data availability}

Clinico-chemical data are avaible from the Open Science Framework on https://osf.io/fhgwt/.

Microbiomic data are available at the NCBI Bioproject on https://www.ncbi.nlm.nih.gov/bioproject/752003.

\section{Funding}

The running costs and LK were funded by the Danish 3R Centre (Grant No 33010-NIFA-18-691) (en.3rcenter.dk/) and the Novo-Nordisk/Lundbeck/University of Copenhagen Centre for Applied Laboratory Animal Research (www.calar.dk). CMJM was funded by the Novo-Nordisk/University of Copenhagen LIFEPHARM Centre (www.lifepharm.dk). Remaining costs were funded in-house by the University of Copenhagen.

\section{Authors' relationships and activities}

AKH declares that he has collaborated with pharmaceutical industry and received funding from this source, as well as he is the owner of a diabetes related patent as described on https://ivh.ku.dk/english/employees/?pure=en/persons/107126. CHFH declares that she has received funding and collaborated with private enterprises as described on https://ivh.ku.dk/english/employees/?pure=en/persons/306048. DBS declares that she has received funding and collaborated with private enterprises as described on https://ivh.ku.dk/english/employees/?pure=en/persons/114880. PD declares he is an employee of GVG Genetic Monitoring $\mathrm{GmbH}$. Other authors declares no conflicts of interests.

\section{Contribution statement}

AKH launched the idea and the hypothesis; VB and CRL performed the animal studies and the clinical assessments; PD performed the genomic characterization; LK, JLCM and DSN did the microbiomic characterization; DBS and VB set up the handling system for the mice; AKH, VB, CMJM, CRL, JLCM and LK did the statistics; AKH and DSN supervised the study. CHFH, VB and CRL performed insulin and leptin measurements; AKH, VB, CRL and CMJM wrote the first draft of the manuscript and all authors commented and accepted the manuscript.

\section{References}

1. Varga, O., Harangi, M., Olsson, I. A. \& Hansen, A. K. Contribution of animal models to the understanding of the metabolic syndrome: a systematic overview. Obes Rev, 11, 792-807 https://doi.org/doi:10.1111/j.1467-789X.2009.00667.x (2010).

2. Potts, J. E. et al. The Effect of Glucagon-Like Peptide 1 Receptor Agonists on Weight Loss in Type 2 Diabetes: A Systematic Review and Mixed Treatment Comparison Meta-Analysis. PLoS One, 10, e0126769 https://doi.org/doi:10.1371/journal.pone.0126769 (2015).

3. Nuffer, W. A., Trujillo, J. M. \& Liraglutide A New Option for the Treatment of Obesity. Pharmacotherapy: The Journal of Human Pharmacology and Drug Therapy, 35, 926-934 https://doi.org/doi:10.1002/phar.1639 (2015).

4. Kalra, S., Kalra, B., Kumar, S. \& Sharma, A. Managing insulin resistance: role of liraglutide. Clin Pharmacol, 2, 131-134 https://doi.org/doi:10.2147/CPAA.S10496 (2010).

5. Tamborlane, W. V. et al. Liraglutide in Children and Adolescents with Type 2 Diabetes. N Engl J Med, 381, 637-646 https://doi.org/doi:10.1056/NEJMoa1903822 (2019).

6. Zurita, E. et al. Genetic polymorphisms among C57BL/6 mouse inbred strains. Transgenic Res, 20, 481-489 https://doi.org/doi:10.1007/s11248-0109403-8 (2011).

7. Rasmussen, T. S. et al. Mouse Vendor Influence on the Bacterial and Viral Gut Composition Exceeds the Effect of Diet. Viruses, 11, 588160 https://doi.org/doi:10.3390/v11050435 (2019).

8. Yang, Y. B., Smith, D. L., Keating, K. D., Allison, D. B. \& Nagy, T. R. Variations in Body Weight, Food Intake and Body Composition after Long-Term High-Fat Diet Feeding in C57BL/6J Mice. Obesity, 22, 2147-2155 https://doi.org/doi:10.1002/oby.20811 (2014).

9. Festing, M. F. On determining sample size in experiments involving laboratory animals. Lab Anim, 52, 341-350 https://doi.org/doi:10.1177/0023677217738268 (2018).

10. Cani, P. D. et al. Changes in gut microbiota control metabolic endotoxemia-induced inflammation in high-fat diet-induced obesity and diabetes in mice., 57 , 1470-1481 (2008).

11. Turnbaugh, P. J. et al. An obesity-associated gut microbiome with increased capacity for energy harvest., 444, 1027-1031 (2006).

12. Dobrowolski, P., Fischer, M. \& Naumann, R. Novel insights into the genetic background of genetically modified mice. Transgenic Res, $27,265-275$ https://doi.org/doi:10.1007/s11248-018-0073-2 (2018).

13. Richter, S. H., Garner, J. P. \& Würbel, H. Environmental standardization: cure or cause of poor reproducibility in animal experiments? Nat. Methods, 6, 257261 https://doi.org/doi:10.1038/nmeth.1312 (2009). 
14. Kollias, G. et al. Animal models for arthritis: innovative tools for prevention and treatment.Ann.Rheum.Dis.(2011)

15. Bleich, A. \& Hansen, A. K. Time to include the gut microbiota in the hygienic standardisation of laboratory rodents. Comparative immunology, microbiology and infectious diseases, 35, 81-92 (2012).

16. Siersbæk, M. S. et al. C57BL/6J substrain differences in response to high-fat diet intervention. Sci. Rep, 10, 1-15 (2020).

17. Hufeldt, M. R., Nielsen, D. S., Vogensen, F. K., Midtvedt, T. \& Hansen, A. K. Variation in the Gut Microbiota of Laboratory Mice Is Related to Both Genetic and Environmental Factors. Comp. Med, 60, 336-342 (2010).

18. Wurbel, H. Behaviour and the standardization fallacy. Nat. Genet, 26, 263-263 (2000).

19. Richter, S. H., Garner, J. P., Auer, C., Kunert, J. \& Würbel, H. Systematic variation improves reproducibility of animal experiments. Nat. Methods, 7, 167-168 https://doi.org/doi:10.1038/nmeth0310-167 (2010).

20. Bodden, C. et al. Heterogenising study samples across testing time improves reproducibility of behavioural data. Sci. Rep, 9,9 https://doi.org/doi:10.1038/s41598-019-44705-2 (2019).

21. Payseur, B. A. \& Cutter, A. D. Integrating patterns of polymorphism at SNPs and STRs. Trends in Genetics, 22, 424-429 https://doi.org/doi:10.1016/j.tig.2006.06.009 (2006).

22. Mahler Convenor, M. et al. FELASA recommendations for the health monitoring of mouse, rat, hamster, guinea pig and rabbit colonies in breeding and experimental units. Lab Anim, 48, 178-192 https://doi.org/doi:10.1177/0023677213516312 (2014).

23. Hurst, J. L. \& West, R. S. Taming anxiety in laboratory mice. Nat Methods, 7, 825-826 https://doi.org/doi:10.1038/nmeth.1500 (2010).

24. Krych, L. et al. Have you tried spermine? A rapid and cost-effective method to eliminate dextran sodium sulfate inhibition of PCR and RT-PCR. $J$ Microbiol Methods, 144, 1-7 https://doi.org/doi:10.1016/j.mimet.2017.10.015 (2018).

25. Ellekilde, M. et al. Characterization of the gut microbiota in leptin deficient obese mice - Correlation to inflammatory and diabetic parameters. Res Vet Sci, 96, 241-250 https://doi.org/doi:10.1016/j.rvsc.2014.01.007 (2014).

26. Charpentier, J. et al. Liraglutide targets the gut microbiota and the intestinal immune system to regulate insulin secretion. Acta Diabetol, 58, $881-897$ https://doi.org/doi:10.1007/s00592-020-01657-8 (2021).

27. Everard, A. et al. Cross-talk between Akkermansia muciniphila and intestinal epithelium controls diet-induced obesity. Proc Natl Acad Sci U S A, 110, 9066-9071 https://doi.org/doi:10.1073/pnas.1219451110 (2013).

28. Cani, P. D. et al. Changes in gut microbiota control metabolic endotoxemia-induced inflammation in high-fat diet-induced obesity and diabetes in mice., 57, 1470-1481 https://doi.org/doi:10.2337/db07-1403 (2008).

29. Depommier, C. et al. Supplementation with Akkermansia muciniphila in overweight and obese human volunteers: a proof-of-concept exploratory study. Nat Med, 25, 1096-1103 https://doi.org/doi:10.1038/s41591-019-0495-2 (2019).

30. Million, M. et al. Obesity-associated gut microbiota is enriched in Lactobacillus reuteri and depleted in Bifidobacterium animalis and Methanobrevibacter smithii. Int J Obes (Lond), 36, 817-825 https://doi.org/doi:10.1038/ijo.2011.153 (2012).

31. Wang, J. J. et al. Enterotype Bacteroides Is Associated with a High Risk in Patients with Diabetes: A Pilot Study. Journal of Diabetes Research 2020, doi:10.1155/2020/6047145 (2020)

32. Gu, Y. Y. et al. Analyses of gut microbiota and plasma bile acids enable stratification of patients for antidiabetic treatment. Nat. Commun, 8 , https://doi.org/doi:10.1038/s41467-017-01682-2 (2017).

33. Russell, W. M. S. \& Burch, R. L. The Principles of Humane Experimental Technique1-238(Methuen \& Co Ltd., 1959).

34. Hansen, A. K., Hansen, F., Krych, C. H., Nielsen, D. S. \& L. \& Impact of the gut microbiota on rodent models of human disease. World journal of gastroenterology: WJG, 20, 17727-17736 https://doi.org/doi:10.3748/wjg.v20.i47.17727 (2014).

35. Pyndt Jorgensen, B. et al. Investigating the long-term effect of subchronic phencyclidine-treatment on novel object recognition and the association between the gut microbiota and behavior in the animal model of schizophrenia. Physiol Behav, 141, 32-39

https://doi.org/doi:10.1016/j.physbeh.2014.12.042 (2015).

36. Hansen, C. H. F. et al. Early life treatment with vancomycin propagates Akkermansia muciniphila and reduces diabetes incidence in the NOD mouse., 55, 2285-2294 (2012)

37. Zachariassen, L. F. et al. Sensitivity to oxazolone induced dermatitis is transferable with gut microbiota in mice. Sci. Rep, 7, 44385 https://doi.org/doi:10.1038/srep44385 (2017).

38. Chen, G. Y. The Role of the Gut Microbiome in Colorectal Cancer. Clin Colon Rectal Surg, 31, 192-198 https://doi.org/doi:10.1055/s-0037-1602239 (2018).

\section{Figures}

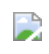

Figure 1

Protein: $20 \% \mathrm{kcal}$, Fat: $60 \% \mathrm{kcal}$, Carbohydrate: $20 \% \mathrm{kcal}$ ) ad libitum from the age of four weeks to termination (Figure 1) monitoring food intake per cage and individual body weights Monday, Wednesday, and Friday. 


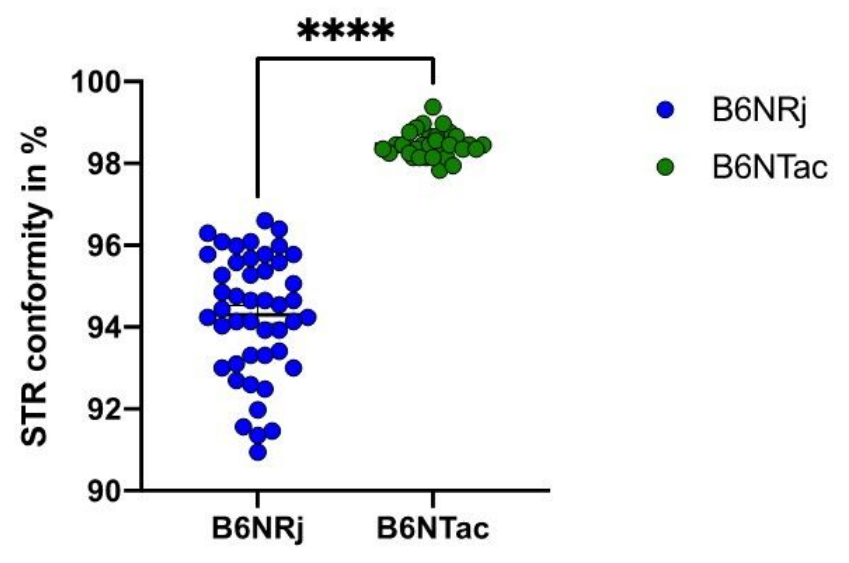

Figure 2

The genetic conformity of the B6NTac mice was significantly higher than the B6NRj mice $(p<0.0001$, Figure 2$)$.

\section{Supplementary Files}

This is a list of supplementary files associated with this preprint. Click to download.

- DataS2.xIsx

- DataS3.pptx

- Tables1.docx

- Tables2.docx

- Tables3.docx 